\title{
Stakeholders and Corporate Social Responsibility (CSR): A New Perspective on the Structure of Relationships
}

\author{
Nobuyuki Tokoro \\ Tamagawa University, 6-1-1 Tamagawagakuen, Machida-shi, Tokyo 194-8610, Japan. \\ E-mail: tokoronbk@aol.com
}

This paper analyses the characteristics of relationships between stakeholders and corporate social responsibility (CSR) and stakeholders. Previous researches on relationships between enterprises and stakeholders have demonstrated two characteristics, of 'restriction' and 'transaction', but they do not appear to shed much light on recent developments. This is partly due to the new trend of corporate dialogue with stakeholders, aimed either at addressing social issues or with a view to acquiring a positive perception through such dialogue; we see this process as one of 'value creation'. Stakeholder dialogue is more established in Europe, where CSR has developed most extensively, than elsewhere. Today, European enterprises are moving towards a standardized system to formalize and evaluate the value of stakeholder dialogue. Japanese opinion, however, is not always in favor of such standardization, as in Nonaka' Knowledge Creation Theory, which argues that all innovation is produced through a creative process of solving contradictions and conflicts, rather than through applying objective processes. This paper discusses the context of stakeholder dialogue and the Japanese perception of its application. Asian Business \& Management (2007) 6, 143-162. doi:10.1057/palgrave.abm.9200218

Keywords: stakeholder; restriction; transaction; value creation; dialogue; social context

\section{Introduction}

Two central developments in the business world towards the end of the 20th century were globalization and the increasing dominance and impact of information technology ('informaticization'), and these developments have continued to accelerate in the early 21 st century. The principal triggers for this increasing globalization and informaticization have been the continuing structural collapse and/or shift to a market economy of the former Communist countries, and, starting in the USA, the IT revolution, based mainly on the spread of the Internet. Attention is thus now being paid to those changes continuing on from 
the 20th century. Among Japanese corporations, Toyota, Honda, and Sony have become increasingly internationalized, and the current situation is such that, to quote the Honda CEO, 'National borders have no meaning for corporations' (Nikkei Business, 6 December 2005-2 January 2006, 37).

However, when management studies researchers try to establish a profile of business management for the 21 st century, do they need to restrict their focus to the twin perspectives of globalization and informaticization in order to investigate the relationship with the performance of financial government, and to assess the issues in increasingly logical terms? The answer is 'No' - because, although globalization and informaticization are necessary conditions for 21 stcentury business management, they are not sufficient conditions.

This point can be clarified by an overall assessment of whether the 20th century was a century just like any other. Material culture was at a higher level during the 20th century than in any previous century, but what made this possible was a system of social economy based on mass production and consumption, in turn made possible by rapid advances in science and technology. Within this system, corporations competed for sales and market share, and have followed a path of quantitative expansion. As a result, at least in the developed world, an affluent society, with surpluses in both production and consumption, has come into being. On the other hand, however, the economic system based on mass production and consumption has led to great increases in the wasteful consumption of resources and pollution, and thus to deterioration in the global environment. Since the 1980s, ever-increasing volumes of scientific data have shown deterioration in the global environment, leading to increased international concerns about environmental crisis, and thus increasingly strong pressure on corporations to take environmental issues into account in their activities.

The socioeconomic atmosphere that has come into existence is thus one in which it is considered unacceptable for corporations to concentrate solely on avoiding falls in sales and market shares, to the exclusion of concern for the global environment. The trend is that corporate globalization and informaticization have continued to strengthen, yet there has emerged an increasingly strong demand for corporations to put into practise a stakeholders and corporate social responsibility (CSR) management system, in which equal weight is accorded to the economic, environmental, and social aspects of their activities.

As an introduction, the main point emphasized in the current article is that, in an analysis of the structure of 21st-century business management, the pivotal phenomena of management, globalization and informaticization cannot, as in older corporate models, be satisfactorily evaluated solely through the filters of sales, market share, and/or return on equity, as there is the possibility of missing certain real changes in business management. In order for corporations to continue in existence and achieve competitive advantage in the 21 st century, 
the most important thing is to be accepted and approved by society, and the requirements that society makes of companies have clearly changed. In other words, society is starting to demand that companies move their focuses from quantitative expansion to qualitative improvement. This trend must not be overlooked, and represents an important feature of the difference between 20th- and 21st-century business management.

In the present article, the focus is on analysing the relationships between corporations and society in the midst of this ongoing change. In this context, the relationships between corporations and society will be replaced by those between CSR and stakeholders. The reason for this is that, from the point of view of a corporation, various stakeholders have connections with corporate activities, and society is one of these stakeholders, and, furthermore, the qualitative improvements in management demanded by society are in effect the same as CSR. For the present article, on the basis of a review of previous research about the connections between corporations and stakeholders and between CSR and stakeholders, and a theoretical evaluation of that research, corporate case studies were carried out, involving interviews with stakeholders, in order to identify the links to increasing corporate value, and to look towards problems that may result from these new connections.

\section{Stakeholders and Business Management}

The initial aim of this article is to review previous research on the relationships between stakeholders and business management, with procedures adding logical assessments. In management theory, since Taylor's development in 1911 of a theory of scientific management, issues of management within corporate organization have been central to the field, and the relationships between a corporation and its surrounding environment have been seen as outside the scope of concern. ${ }^{1}$

The first case of research focusing on the relationships between corporations and their external environments was Burns and Stalker (1961). They evaluated 20 UK companies, and clearly showed that external environments affected internal organization. Their findings were that, if a company's external environment is stable, with few factors that cannot be predicted and/or controlled by the company in question, that company's management system tends to be highly regulated, with a clear hierarchical system for procedures, authority and responsibility; whereas if the external environment is unstable, with many unpredictable and uncontrollable factors, rules, procedure, authority and responsibility tend to be ill-defined, and authority tends to be diffuse, with a high degree of freedom in decision-making. Burns and Stalker termed the former a 'mechanistic management system', and the latter an 'organic management system'.2 In addition, Lawrence and Lorsch (1967) 
surveyed 10 R\&D, manufacturing and sales departments, and demonstrated that differences in the external environments directly surrounding each department affected organizational structure, leadership, and aspirations within those departments. Research approaches of this type, concerned with the relationships between corporate organization and external environment, are termed 'contingency theories', and represent a new wave in the field of organization theory that developed in the 1960s and 1970s. Contingency theory presents an open-system perspective on corporate organization, with increased emphasis on the effects on corporate organization of the external environment, in contrast with the older closed-system perspectives in organization theory, in which the relationships between inside and outside the corporation were left out of the field of view.

On the other hand, there has also been research on the relationships between the external environment and the internal organization, with analysis from the point of view of transaction costs. The work of the systems-economists, such as Williamson (1975), represents such a transaction-cost approach. Their findings suggest that the relationships between a company and its environment determine the mechanism for resource transaction. The two types of mechanism by which resources can be supplied are a market mechanism and a corporate in-house mechanism, and the factor determining which mechanism will operate is the transaction cost. The decision-making personnel are assumed to select the mechanism that minimizes transaction costs.

From the point of view of resource-transaction costs between corporate organizations and external environment, Pfeffer and Salancik (see Kuwata and Tao, 1998) developed the resource-dependence perspective, on the basis of theoretical research on the bi-directional connections. In this resourcedependence perspective, the structure of relationships between the organization in question and other organizations explains the exchange of resources with other organizations, and the times at which such resource transactions occur. Using this model, resources controlled by the organization itself and by other organizations are compared, and, in cases of successful resource transfer, interorganizational relationships are established. However, in these inter-organizational transactions there are differences in the importance, scarcity, etc., of resources controlled by organizations, and for this reason the relationships can often be classified as being subordinate or non-subordinate in type. In other words, organizations that control resources that are of marked importance to other organizations can take up a position of dominance with respect to those organizations, which thus have a high degree of dependence on the resourcecontrolling organization. In this resource-dependence perspective, relationships of the above type are explained in terms of 'power superiority', and it is assumed that most organizations strive to reduce their dependence on other organizations as far as possible, in order to be autonomous. 
Most research on relationships between companies and their surrounding environments was carried out in the 1960s and 1970s, and a number of highly influential theories were developed. During the 1980s, companies' external environments became more complicated, and an important theme in studies came to be how to respond to the external environment at the same time as making smooth and efficient progress in corporate activities. Freeman (1984) defined a stakeholder as any group or individual that affects, or is affected by, the achievement of a company's aims, and he indicated the importance of the stakeholder approach in business management.

Previous research on relationships between corporate organization and external environment is summarized above. If, on the basis of this research, one wishes to find keywords to apply to these relationships, they are 'restrictions' and 'transactions'. That is, contingency theory suggests that differences in external environment will affect corporate organization, so the external environment can be seen as a restrictive factor in corporate organization, whereas with the transaction-cost approach and resource-dependence model, the relationships between organizations and external environments are viewed as aspects of a resource-transaction relationship. If the term 'external environment' is replaced with 'stakeholder', these previous research findings can be interpreted as showing that the existence of stakeholders is a restrictive factor from the perspective of a company, and/or that stakeholders are partners in resource transaction. Nevertheless, previous research treated the external environment was as a given, and was thus only concerned with the effects of the external environment on corporate organization; there has been insufficient interest in the opposite case, that of corporate organization affecting the external environment. However, in the real world, corporate organization can affect the external environment; companies act on stakeholders in various ways; and companies often strive to establish favourable external environments. Effects working in this direction cannot be explained on the basis of theories used in previous research.

Together with an increasing awareness of the importance of connections between business management and the external environment, increasing attention has been given to the societal roles and responsibilities of companies, which is the problem of the relationship between stakeholders and CSR. This area is discussed in the next section.

\section{Stakeholders and Corporate Social Responsibility}

This section is concerned with the connections between CSR and stakeholders. In the way of thinking that spread in the USA and various European countries in the late 1990s, CSR is the concept that provides theoretical support for the 
transformation in business management from striving for quantitative expansion to striving for qualitative improvement. However, there is at present no comprehensive definition of CSR. Therefore, although there are measures of some sort for evaluating CSR, in practice, this is carried out by means of a CSR framework, consisting of a triple bottom line of economic, environmental and social issues. ${ }^{3}$ An important issue is what stakeholder relationships are when business management is assessed from the point of view of CRS.

Considering, for example, the case of shareholders, these being some of the most important stakeholders in a corporation, they generally want good returns on their investments, and thus demand high profits, growth and share prices. If these are not achieved, they put pressure on management, via the shareholders' committee, or they simply sell their shares. In other words, the actions of shareholders constitute a major restrictive factor on a corporation's activities. On the other hand, there have been actions taken by shareholders in the context of CSR, and the roles of socially responsible investment (SRI) funds can be given as an example in this respect. SRI funds have an approach to investment that involves taking social and environmental factors into account in addition to financial performance when selecting the companies with which to invest, and these funds maintain a strong position, especially among institutional investors such as pension funds, in Europe and the USA. ${ }^{4}$ One of the tools used by SRI funds for selection of companies in which to invest is called 'negative screening'. This involves comparing companies with ethical criteria, and eliminating companies engaged in ethically unacceptable corporate activities. Such activities include paying low wages, having unsafe and/or unhygienic working conditions, using child labour, discriminating against ethnic minorities, polluting the environment, and supporting dictatorial regimes. If the fund judges a company to be problematic in one or more of these respects, the fund eliminates it from its list of investment-worthy companies, or, if it has already invested in it, it sells up and severs connection. In addition, shareholder activism is a method used by SRI funds. What this means is that the fund requests the companies in which it is to invest to act in accordance with the social and/or environmental concerns on which the shareholders place importance; that is, shareholders use those rights that they have, such as the rights to make decisions, to put forward motions, and to have lawsuits brought on their behalf. ${ }^{5}$ When these options are taken into consideration, shareholders, as stakeholders, can also be seen to function as restrictive factors on CSR.

Another issue is the relationships between CSR and not-for-profit organizations (NPOs), which are increasingly being seen as stakeholders. These NPOs, which form a third sector, in addition to government and business, have in recent years become increasingly active in fields such as 
welfare, environmental protection, and education, and are in the process of establishing various relationships, as stakeholders, with the CSR actually carried out by corporations. As the aims and organizations of profit-making companies and NPOs are fundamentally different, there is little mutual understanding, and their relationships are therefore usually considered to be antagonistic or distant. When companies pollute the environment or have poor working conditions through prioritizing the pursuit of profit, they are sometimes vigorously criticized or aggressively exposed by NPOs. In this context, the following two international examples can be given:

1. The first company is Royal Dutch - Shell Group (Shell), a huge oil corporation. In the mid-1990s, two events occurred with gas extraction, which is the most important part of Shell's business. One of these was the problem of how to dispose of Brent Spar, an oil-storage and tanker-loading platform in the North Sea, and the other was its standing with respect to the Nigerian human-rights activist, Ken Saro-Wiwa, who was executed for his opposition to Nigeria's military dictatorship. With respect to Brent Spar, Shell proposed towing the redundant platform into the Atlantic Ocean, and sinking it in deep water, but NPOs such as Greenpeace objected to this on the grounds that it would result in water pollution, and organized an extensive boycott of Shell petrol stations. In the case of Saro-Wiwa, Shell's heavy involvement in Nigeria's economy brought it under pressure from the Nigerian government, so it was loath to get involved in politics, and made no effective response. Shell was thus subjected to intense criticism from human rights NPOs, as having been cowed by political pressure, and putting profits first.

2. The second company was Nike, a large, global sportswear manufacturer. Nike does not run its own factories, and instead, in order to increase profits, follows an out-sourcing business model, in which manufacturing is contracted out to low-cost Chinese and South-East Asian factories. However, these factories have been sharply criticized by NPOs for having poor working conditions, involving very low wages, child labour, and sexual harassment. Initially, Nike maintained that these issues had nothing to do with Nike itself, being problems with the contract companies, and it therefore made no response to the NPOs' demands for amelioration, but this led to a large-scale boycott of Nike's goods, which had a marked negative impact on company profits.

The above cases are well known, but there have been numerous similar examples of hostile interactions between companies and NPOs. To summarize, it is clear that NPOs act as stakeholders, and are thus restrictive factors on CSR. 
Finally, one entity that has an important role as a stakeholder with respect to CSR is the United Nations (UN). The UN has hosted three large-scale international conferences on global environmental protection, at Stockholm (1972), Rio de Janeiro (1992), and Johannesburg (2002), and has played an important role in the international trend towards environmental protection. At this point it is necessary to explain about the Global Compact. The Global Compact was put forward by UN President Kofi Annan at the Global Economic Forum, held at Davos in January 1999. Annan asked global business leaders to bear in mind the need for all the world's inhabitants to benefit from globalization, and his proposed Global Compact consisted of 10 basic principles, in the four areas of human rights, labour, environment and anti-corruption. Companies supporting these 10 principles pledge to abide by them, and to report yearly to the UN about their activities in these respects. In the case of companies that have signed the Global Compact, it is possible that, rather than their being motivated by an agreement with, and desire to follow, the 10 principles, their aim is to achieve status as brands that are trusted and respected by the $\mathrm{UN}$, a body with very high public status. In this case, the relationship between the companies in question and the UN can be seen as one of resource exchange.

\section{Stakeholder Dialogue}

Up to this point, the areas considered have been relationships between stakeholders and business management, and between CSR and stakeholders, with the focus on CSR. However, it has become clear in this discussion that relationships between companies and stakeholders can be explained in terms of two items: (i) restrictions and (ii) exchange. In other words, from the points of view of companies, stakeholders function as restrictive factors in some respects and as resource-exchange partners in others. Therefore, when companies pay attention to their relationships with stakeholders, the specific characteristics of these relationships have come to be the fundamental basis of the assessment, and researchers analysing these relationships take similar approaches. However, there has been a change in relationships between companies and stakeholders, which has added a new property: value creation. This is particularly marked in the case of relationships between CSR and stakeholders. As explained above, the characteristics of these relationships can be either restrictive or exchange-oriented, but, in the new, increasingly widespread, trend, energetic dialogue takes place between companies and stakeholders, and the attempt to identify new business management perspectives in this dialogue cannot be explained solely in terms of the above two characteristics. 
In terms of either business management as a whole or individual problems, since the later 1990s there has been a marked trend towards intensive stakeholder dialogue (ie dialogue with stakeholders). In the above cases, Shell and Nike, after suffering severe criticism, engaged upon energetic stakeholder dialogue, with the aim of recovering their corporate standing. In the case of Japanese companies also, Toyota Motor Corp. and Matsushita Electric initiated stakeholder dialogue in 2001, and other companies are following suit.

The question now is why companies find stakeholder dialogue important, and the answer to this concerns the essence of CSR. That is to say, as globalization and informaticization have accelerated, the connections between stakeholders and business management have become increasingly diverse and complex, and it has ceased to be the case that all companies have to do to satisfy their stakeholders is to increase profits and keep growing. For example, in the Nike case, the out-sourced production business model, developed in order to maximize profits, involved repeatedly changing factories to which work was contracted, on the basis of each factory's cost performance, but the NPOs involved in supporting the employees who worked at factories that lost their contracts, and were thus made unemployed, criticized Nike intensely for the use of this business model. Unless companies pay close attention to the demands and opinions of various types of stakeholder, and keep striving to include these within the process of business management, they cannot guarantee continued existence in the 21 st-century marketplace. It is for this reason that stakeholder dialogue has become such a useful tool for companies. It can be said that this activity is, in itself, CSR.

If stakeholder dialogue is taken to be a significant tool in business management, various methods can be considered. Figure 1 shows stakeholder dialogue organized on the basis of a four-stage division.

In Figure 2, added value for the whole of society is the vertical axis, and the frequency and intensity of relationship is the horizontal axis, with relationships classified in the four following categories, depending upon the degree of development: (i) information release; (ii) opinions canvassed; (iii) dialogue; and (iv) collaboration. For example, if the relationship is one of information

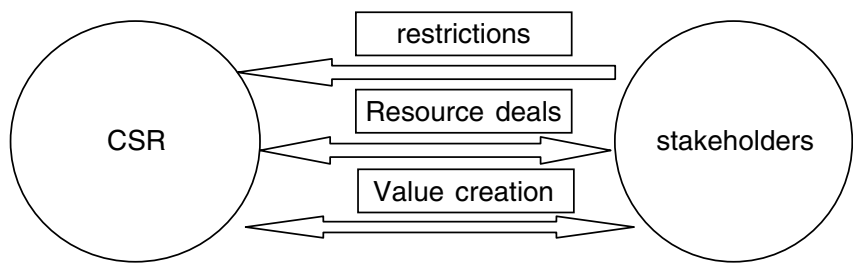

Figure 1 Relationships between CSR and stakeholders. 


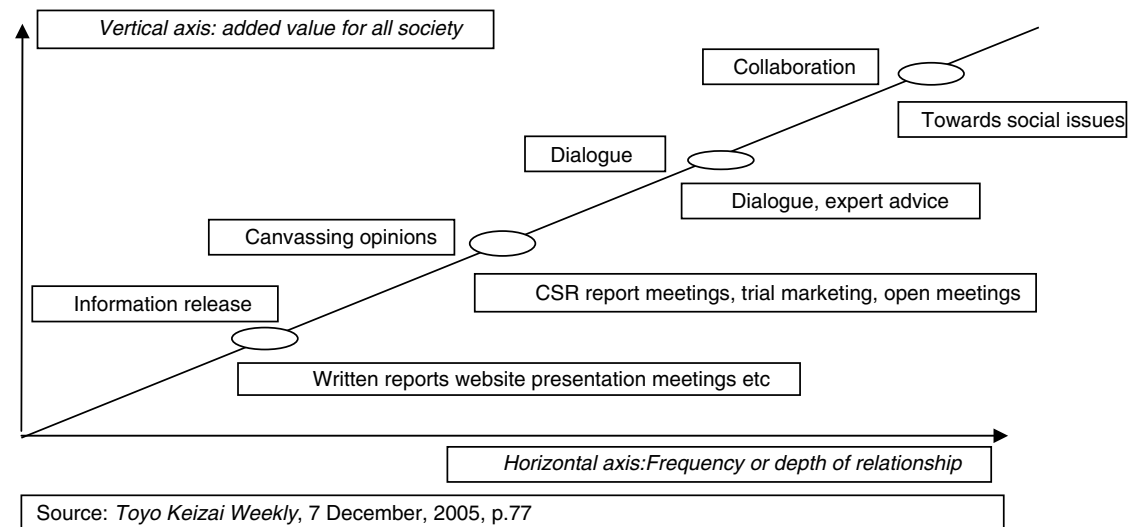

Figure 2 Progressive stages of development for dialogue. Source: Toyo Keizai Weekly, 7 December 2005, p. 77.

release, at the lowest level, communication is one-way, from the company, and the stakeholder to which it is communicated has little involvement with the company. The main methods used with this category include publication of CSR reports, release of information on homepages, and holding explanatory meetings.

At the next level, with a relationship involving listening to opinions, dialogue (two-way communication) takes place to some extent, and the main method involves holding CSR report meetings, attended by a large number of unspecified people from outside the company. There is the possibility that those attending these meetings will put forward points of view that have not been put forward at in-house meetings, but there is also the risk that the discussion will have no defined focus and little content. At the next level up, there is true dialogue, with the potential for the expanded discussion of issues that have arisen. The method used involves the companies gathering experts in a particular issue and providing a place for them to freely debate, in the hope that problematic points will be identified and verified, and approaches to resolution will be put forward. For example, a company may specify as a theme the problems with environmental management with which it is involved, and then invite personnel from governmental bodies, investors, NPOs, universities, etc., to gather and discuss this theme in a focused manner.

The highest level is collaboration, which means that companies and stakeholders do not merely discuss issues, but are involved in practical mutual activities. For example, companies and NPOs may cooperate in environmental protection, or may collaborate in establishing groups for children's environmental education. Although this collaboration is placed at the highest level, the 
dialogue between companies and stakeholders actually involves the following two processes:

1. The company discusses the methods to be used to enable collaboration. For example, in the above case of a company and an NPO cooperatively setting up and running an environmental education group, there will be dialogue between the two parties as to the aims of the group, and its operational procedures. This stage can be termed the pre-collaboration dialogue.

2. Direct dialogue from various perspectives.

As an example of the first type of dialogue, in the above example of setting up an educational group, if there is disagreement between the two parties about operating methods, or if new ideas about the operation are needed, the dialogue is carried out from various points of view. The dialogue at this stage is termed mid-collaboration dialogue. There are also cases of post-collaboration dialogue, after the specified collaborative period has ended, and the results of the collaboration have been pooled and assessed. In either case, dialogue at this stage requires concrete results, and mutual understanding between companies and stakeholders is therefore indispensable, with there also being a need for the consistent use of terms by the two parties.

An important point with respect to stakeholder dialogue is the need to strive to ensure that dialogue between the two parties continues after the formal dialogue ends. That is to say, a more important issue for a company than actually carrying out stakeholder dialogue is knowing that the outcome of that dialogue has the potential to influence the company's management, and that a corporate system must therefore be designed to ensure that the results of dialogue are fully grasped and taken into consideration. If this system design is ineffective, there is the risk that the stakeholder dialogue will in the end have been nothing more than an exchange of opinions. Figure 3 shows the design of a system for making full and effective use of stakeholder dialogue.

The first step in designing a dialogue system must be for the company in question to achieve a full understanding of its internal and external environments. This should involve as accurate an understanding as possible of the problems with which the company is confronted externally and internally, and the issues that will have to be overcome in order to continue to grow. In achieving this understanding, the important issue that will arise is what is hoped to be achieved from the stakeholder dialogue. As the second step in system design, the existence of stakeholders connected with the corporate process must be acknowledged, and an understanding should be achieved as to their current and hoped-for links with the company. The diversity of stakeholders is affected by the nature of the company, such as its field of business, its size, and whether it is global or national. The company must acknowledge the existence of important 


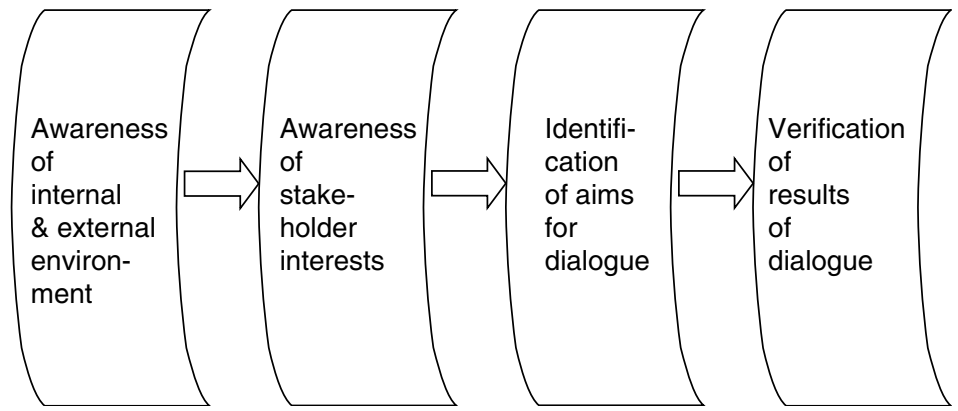

Figure 3 Designing systems for stakeholder dialogue.

stakeholders, and then analyse its connections with them, involving an understanding of the details of their and its activities.

The third step is to define the aims and targets of the dialogue. In other words, the company's problematic issues and its stakeholders' activities are analysed in steps 1 and 2, and, on the basis of the results of that analysis, in step 3 the stakeholders with which the dialogue is to be held are defined, and the aims of the dialogue clarified. For example, a concrete decision must be made as to whether opinions are canvassed from a large and undefined number of stakeholders about environmental management, or whether the dialogue is just to be with stakeholders specifically concerned with local society. Finally, the fourth step consists of verifying the results of the dialogue. As mentioned above, to ensure that dialogue does not end with the completion of formal dialogue, the results of the dialogue are verified, and the strategic value of those results must be ascertained and acknowledged. However, one point to which attention must be given in this respect is that the results of dialogue do not necessarily all have short-term or immediate effects. For example, in terms of outcome, such things as increased sales or share prices may be expected, but it is also necessary to recognize the possibility of more long-term positive results, such as establishment of the company as a brand perceived to be reliable and trustworthy.

In the case of Japanese companies also, a tendency has started to make a connection with value creation through stakeholder dialogue. The next section presents the case of stakeholder dialogue at two levels, those of dialogue and collaboration.

\section{Case Studies}

\section{Dialogue level: Sagawa Express}

Sagawa Express, a general light haulage company involved in deliveries, house removals, and transport, is known to be heavily involved in trying to reduce the 
carbon dioxide emitted by its fleet of lorries. ${ }^{6}$ In the light haulage industry there is intense pressure to reduce costs, and increasing oil prices also contribute to a severe business environment, but Sagawa Express recognizes that, in order to continue to thrive in the long term as a general light haulage company, it is necessary to achieve public trust and respect, and thus to respond energetically to environmental concerns. Sagawa Express has put 'green transport' forward as its management target, and since 2004 it has been holding stakeholder dialogue with this objective.

The following four meanings for stakeholder dialogue have been put forward by Sagawa Express:

1. The establishment of a system to enable the opinions and concerns of the general public to be reflected in the activities of Sagawa Express.

2. The aim of making flexible responses to various kinds of stakeholder.

3 . The publication of press releases and other information about activities through which the company impacts upon society.

4. With the aim of becoming the number-one general light haulage company in East Asia, the establishment of a company delivering excellent performance.

At the 'Second Sagawa Stakeholder Dialogue', held in September 2005, the theme set was how to put green transport into practice in the marketplace, and the stakeholders invited to participate were local government personnel, academics and other experts, lawyers, NPOs, and personnel from other businesses and the mass media. These were all requested to complete and return a questionnaire beforehand. The two sections in the questionnaire were concerned with (i) the feasibility of, and difficulties with, the expansion and extension of green transport, and points to which attention should be made in this respect, and (ii) requirements for and opinions about Sagawa's stakeholder dialogue. On the basis of the results of this questionnaire, six keywords were selected as targets for the expansion of dialogue, and dialogue continued with these keywords as bases for discussion. This approach has been shown to be effective, and stakeholders have put forward various opinions and proposals in the dialogue, with an energetic exchange of opinions. For example, an understanding of haulage is indispensable for making progress with green transport, but there is currently little information for an objective analysis of how much attention different light haulage companies pay to the environment, and it is difficult to make any judgments about hauliers. One opinion expressed was that, in order to facilitate such judgments, it is perhaps necessary to present objective data on, for example, the environmental impact of a lorry travelling from Tokyo to Osaka. An additional point was that transport companies compete on the service they provide, including such issues as nextday or specific-date delivery, but such speed, accuracy, and reliability cannot be guaranteed if green transport is pursued, that is if transport is to take the 
environment into account, it is unavoidable that more time and expense will be involved than usual, and it will no doubt be necessary to emphasize this point to customers. To this end, one suggestion put forward was that it would be necessary to specify cost differentials between ordinary and green haulage methods. Sagawa Express has decided that, although attention is being paid to these opinions and proposals from stakeholders, it is essential to carry out a thorough analysis of their managerial and technical practicality (Nikkei Ecology, 2005).

\section{Collaboration level: NEC and the Asaza Fund}

NEC, a large manufacturer of electrical goods, and the Asaza Fund, which is an environmental NPO, have collaborated in expanding environmental regeneration activities in the Kasumigaura Lowlands in Ibaraki Prefecture. As a representative Japanese corporation, and as a global company that has extended its activities to all parts of the world, NEC recognized the importance of environmental issues at an early stage, and has energetically pursued environmentally oriented management. With respect to relationships with environmental NPOs, too, NEC was one of the first companies in Japan to appreciate their importance, inviting them to participate in the preparation of environmental impact reports, etc., and NEC has come to be known as a company that actively develops such relationships. The Asaza Fund, on the other hand, was an NPO established with the aim of encouraging and facilitating environmental regeneration in the surrounding area. The Fund stated that its objective was to create a natural environment and social system such that the toki crane will still be thriving in Kasumigaura even in one hundred years' time, and it was running the Asaza Project with this aim. The idea was that independent groups, universities, research institutes, and fishery and forestry organizations would participate, forming a network that would realize the Asaza Project's aims. From an early stage in the history of the project, the hope was that a company with a great deal of technological ability would participate, and, after negotiations, NEC, who had a strong wish to form a relationship with an NPO, entered into collaboration with the Asaza Fund. The Fund established a radio-based sensor network system, developed by NEC, at four primary schools that had been studying the Kasumigaura Lowlands biotope, and NEC then presented guidelines for measuring air and water temperature, insolation, etc. This sensor network system had originally been developed for use in monitoring atmospheric pollution; the idea of using it in primary school environmental education had not been one of NEC's initial assumptions, and it was the entirely original suggestion put forward by this NPO that enabled NEC to profit from this unexpected business opportunity. The environmental education provided on the basis of data collected using 20 
sensors set up at four primary schools was evaluated and highly praised, and for this reason it was decided that the sensor should be used at the Aichi Exposition in 2005. The sensor used at the Exposition was an improved version of that used by the Asaza Fund, called Banpaku Amedasu, and was used to collect environmental data, including temperature, humidity, and carbon dioxide concentration at 10-min intervals in the Exposition meeting hall. Having gained this experience, NEC then decided to develop the sensor as a commercial product.

This case of collaboration between NEC and the Asaza Fund is an excellent example of a successful win-win relationship. Although there was sometimes a sense of differences in culture between the company and the NPO during the development process, NEC's appreciation of the NPO's perspective, and the Asaza Fund's clearly defined mission and organization to achieve this, were crucial factors in the success of the collaboration.

\section{Value Creation by Dialogue}

As explained in the previous section, relationships between companies and stakeholders cannot always be classified as either restrictive factors or resource exchanges, as they have been previously, and Japanese companies are starting to join the trend by which dialogue can lead to value creation. This trend is sometimes taken as evidence that the principle of CSR is being more widely accepted by Japanese companies, but it can also be seen as companies increasingly seeking to create value by means of dialogue with stakeholders. In the Sagawa Express case, for example, the stakeholder dialogue is not expected to result in a short-term increase in profits, but is viewed as having an important role in achieving a high evaluation in the marketplace, as a '21st-century light haulage company', and is also considered important for achieving a perspective for management with the aim of maintaining competitive superiority in the long term. Company value must not be thought of as consisting solely of tangible items, such as investments and facilities, but also comprising intangibles such as trust, brand name, and ethical behaviour. ${ }^{7}$ The creation of value by means of stakeholder dialogue can be seen as belonging to the last-named category. It is of course difficult to evaluate a company's intangible property precisely, but it is thought that such property will come to be one of the main sources of corporate competitive strength in this century. Therefore, an increasingly important issue for the analysis of corporate competitiveness is the ability to assess, as accurately as possible, the actual value created by stakeholder dialogue, and a number of differences in the approach to this assessment can be seen between Japan and the West. 
In other words, US and European companies, which are gone further than Japanese companies in the use of stakeholder dialogue, are now striving to develop criteria and rules for such dialogue, in order to reach an accurate understanding of its strategic value. They are aiming to formalize the process and define targets and benchmarks for outcomes, and to make these public. One example of such an approach is AA1000, a set of international criteria prepared by a British NPO called Accountability.

There is a strong feeling among US and European companies that it is necessary to assess as objectively as possible the value creation stemming from stakeholder dialogue. Japanese companies, on the other hand, have only recently started experimenting with stakeholder dialogue, and it is felt to be too soon to debate its outcome. Nevertheless, the top levels of business management are now talking about the need for stakeholder dialogue and/or CSR, but many managers are of the opinion that it will not necessarily be appropriate for Japanese companies to take the kind of approaches, involving defining procedures and stressing objectivity, that US and European companies have taken. Indeed, there is more support for the view that the formal objective approach is highly inappropriate, and that it is difficult to envisage the creation of value arising spontaneously when dialogue is carried out in such a formal manner. As theoretical support for this viewpoint, it may be useful to consider the thoughts of Ikujiro Nonaka and Takeuchi (1996), Nonaka and Konno (2003), Nonaka and Katsumi (2004) and Nonaka et al. (2004), who is globally well known as a supporter of knowledge-creation theory.

Nonaka is well known as a researcher who has closely observed the mechanisms and locations where corporate innovation is achieved and new knowledge created. He has assessed these logically, and established the corporate view of the knowledge base. Nevertheless, he stresses that innovation does not arise through the process of objective theoretical analysis, but, on the contrary, often occurs in the midst of various types of ambiguous, contradictory, and confrontational situations (Nonaka and Katsumi, 2004; Nonaka et al., 2004). Nonaka argues that organizations always contain various contradictions and confrontational elements, and all it needs is a chance event to bring these into the open. There are therefore mechanisms by which, despite there being friction due to contradictions and confrontational elements, points of cooperation can be brought to the fore, and the confrontations resolved. Innovation and creativity are often engendered in this process of resolution.

Attention should be given to ideas such as those of Nonaka in considering the issue of how to appraise value creation through stakeholder dialogue. In other words, when stakeholder dialogue is taking place, the company is in a condition of contradiction and confrontation in which various ideas and types of agreement and criticism are being exchanged, and it has to be expected that on occasion confrontational opinions will be expressed aggressively. The ideas 
and interests of companies, shareholders and NPOs are different, and it should therefore be recognized that in some cases these parties will collide violently. Nevertheless, according to Nonaka, companies ought to welcome such situations, as it is the very process of striving to find points of compromise when opinions clash violently that has the potential to stimulate new perspectives and insights, and to create value. Furthermore, even if stakeholder dialogue does not on the surface appear to involve contradiction and confrontation, and concludes with an expression of approval for the company's approach, although such approval may lead to self-confidence on the part of the company, it is unlikely to result in the creation of new value (Figure 4).

If value creation by means of stakeholder dialogue is looked at in terms of the above, it becomes difficult to accept the US and European approach by which rules are specified for the dialogue process and indices specified for the results. If, in future, under the leadership of Europe and the USA, an international movement for the development of rules for stakeholder dialogue makes headway, it will probably require Japanese companies' compliance, but, leaving this possibility aside, it would seem necessary at present to develop a different, independent Japanese approach.
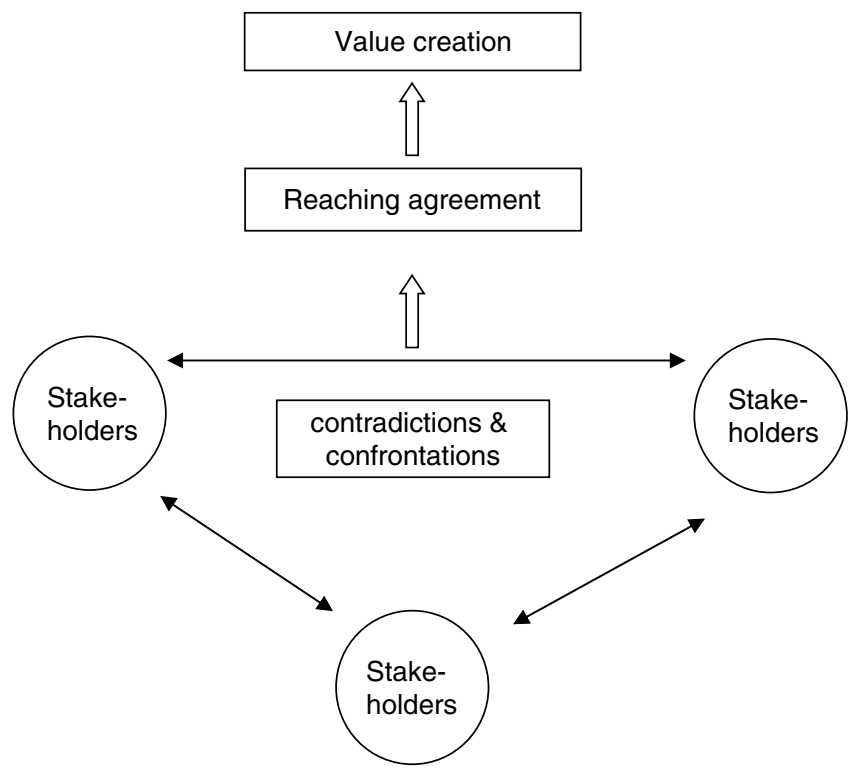

Figure 4 Value creation through dialogue with stakeholders. 


\section{Conclusion}

In this article, it has been explained how, in current understanding, the dynamically changing relationships between companies and society have replaced the relationships between stakeholders and CSR, and the characteristics of these relationships have been analysed. Whereas relationships between CSR and stakeholders have previously been seen as characterized by restrictions and exchanges, the additional characteristic of value creation is now increasingly being accepted. In this article, the possibility that value creation can be achieved by the novel method of stakeholder dialogue has been investigated.

In bringing this article to a close, however, it is important to point out two issues connected with the organization of this new type of relationship:

1. It is necessary to expand the framework for analysing business management. As has been pointed out, management studies researchers have made a start on analysing issues concerning the management of internal corporate organization, and this is gradually being extended to include companies' external environments. It has now come to be the case that the formation of close relationships with various kinds of stakeholders is an indispensable part of business management, and the framework for analysis of business management is thus no longer solely a matter of internal organization, nor can it be focused on a small number of specific stakeholders; it is necessary to change and widen the framework to take into account relationships with a wide range of stakeholders. In other words, there is a need for perspectives that enable companies to be viewed as parts of society.

2. There is a need for qualitative improvements in stakeholders. Even if a company envisages a scenario in which stakeholder dialogue will enable it to create new value, and thus to establish long-term competitive superiority, a precondition for this to happen is the existence of one or more high-quality stakeholders with sufficient perception, discernment and expertise. If no such stakeholders exist, it will be difficult to use them to create new value. In other words, in order to move towards a situation in which there is not just dialogue, but value-creating dialogue, higher stakeholder quality is essential. In the case of Japan in particular, the hope is that many NPOs will undergo qualitative improvement, making them better stakeholders. It has often been pointed out that Japanese NPOs are somewhat late in development in comparison with US and European NPOs; even bearing in mind the fact that Japanese NPOs tend to be poorly funded and to have insufficient human resources, their advocacy skills tend to very limited. In the case of US and European companies also, NPOs are often the principal partners for dialogue. The activities of NPOs are sometimes said to be an index of the maturity of civil society, and it would certainly be a great benefit for Japanese companies if higher-quality NPOs were to develop in Japan. 


\section{Notes}

1 All the different schools of management theory emerging after scientific management theory, including process theory, modern organization theory, and behavioural sciences, have concentrated on internal organization rather than external issues.

2 A considerable amount of research on the relationships between companies' external environments and internal organization has been carried out in the UK, especially at the Tavistock Institute of Human Relations, London. One part of this research is termed 'socio-technical system theory', and is greatly dependent on advances in behavioural science. Examples of researchers working in this area are E. Trist, F.E. Emery, A.K. Rice, and J. Woodward.

3 The 'triple bottom line' was proposed in 1997 by Jon Elkinton, who ran the Sustainability Institute, a UK consulting company, as a novel standard for evaluating companies. The principle is that business management should be evaluated using economic, environmental, and social indices, and this has become the basis for current CSR management. For example, the CSR guidelines published by the Global Reporting Initiative (GRI), a globally influential NGO, were based on this concept, and these guidelines have been accepted by companies in various countries. For details, see http://www.globalreporting.org/.

4 The size of the SRI market in the USA exceeds $\$ 2$ trillion, making up approximately 11 per cent of the US financial market. In Europe, it is approximately $\$ 350$ billion, and is most advanced in Holland and the UK. Pension fund management plays a major role in this sector of the financial market. For details, see http://www.socialinvest.org/.

5 In the USA in the 1970s and 1980s, there was intense criticism of businesses that were involved in South Africa, with its apartheid regime, and many institutional investors, such as pension funds and trades unions, sold their shares in companies operating in that country. For this reason, some large companies such as IBM and GM were forced to markedly reduce their business in South Africa, and this was closely linked to the fall of white rule there.

6 Sagawa Express is a signatory to the WWF's 'Climate Savers' Agreement', and is therefore involved with reducing carbon dioxide emissions. See http://www.sagawa-exp.co.jp/publication/ stakeholder.html.

7 Professor Takayuki Itami of Hitotsubashi University emphasizes that the principal bases of a company's competitive strength are intangible, being the accumulation of technology and knowhow; trust in brand and company name; and a dynamic and stimulating corporate environment. See Itami and Karube, 2004.

\section{References}

Burns, T. and Stalker, G.M. (1961) The Management of Innovation, London: Tavistock. Freeman, R.E. (1984) Strategic Management: A Stakeholder Approach, Boston: Pitman. Itami, H. and Karube, M. (2004) Miezaru Shisan no Senryaku to Ronri [Strategy and Logic of Invisible Assets], Tokyo: Nihon Keizai Shinbunsha.

Kuwata, K. and Tao, M. (1998) Soshiki Ron (Organisation Theory), Tokyo: Yuhikaku Aruma.

Lawrence, P.R. and Lorsch, J.W. (1967) Organisation and Environment, Division of Research, Boston: Harvard Business School.

Nikkei Ecology (2005) Make use of NPO 6: 26-28.

Nonaka, I. and Katsumi, A. (2004) Innovation no Honshitsu [The Essence of Innovation], Tokyo: Nikkei BP.

Nonaka, I. and Konno, N. (2003) Chishiki Sozo no Hohoron [Methodology of Knowledge Creation], Tokyo: Toyo Keizai Shinposha. 
Nonaka, I. and Takeuchi, H. (1996) Chishiki Sozo Kigyo [The Knowledge Creating Company], Tokyo: Toyo Keizai Shinposha.

Nonaka, I., Toyama, R. and Konno, N. (2004) 'Chishiki-beisu kigyo riron [The knowledge-based theory of the firm: Toward dynamic evolution of strategic management]', Hitotsubashi Business Review 52(2): 78-93.

Toyo Keizai (2005) The strongest CSR 5993: 8-122.

Williamson, O.E. (1975) Markets and Hierarchies: Analysis and Antitrust Implications, New York: Free Press. 